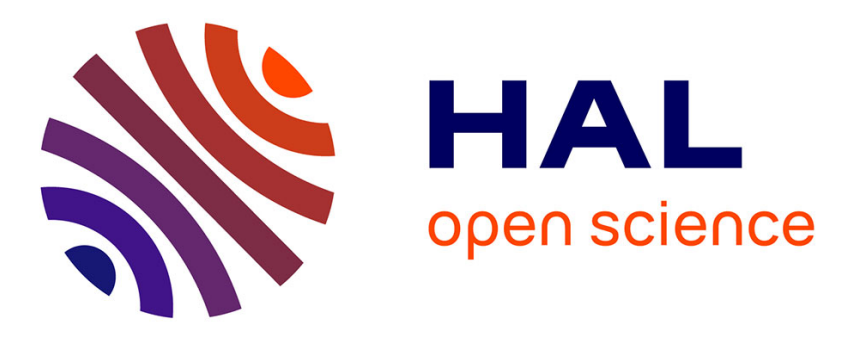

\title{
Self-Assembly and Fluorescence of Tetracationic Liquid Crystalline Tetraphenylethene
}

Jakob Knelles, Stuart Beardsworth, Korinna Bader, Johanna R. Bruckner, Andrea Buehlmeyer, Robert Forschner, Kevin Schweizer, Wolfgang Frey, Frank Giesselmann, Yann Molard, et al.

\section{To cite this version:}

Jakob Knelles, Stuart Beardsworth, Korinna Bader, Johanna R. Bruckner, Andrea Buehlmeyer, et al.. Self-Assembly and Fluorescence of Tetracationic Liquid Crystalline Tetraphenylethene. ChemPhysChem, 2019, 20 (17), pp.2210-2216. 10.1002/cphc.201900569 . hal-02278421

HAL Id: hal-02278421

https://hal-univ-rennes1.archives-ouvertes.fr/hal-02278421

Submitted on 14 Oct 2019

HAL is a multi-disciplinary open access archive for the deposit and dissemination of scientific research documents, whether they are published or not. The documents may come from teaching and research institutions in France or abroad, or from public or private research centers.
L'archive ouverte pluridisciplinaire HAL, est destinée au dépôt et à la diffusion de documents scientifiques de niveau recherche, publiés ou non, émanant des établissements d'enseignement et de recherche français ou étrangers, des laboratoires publics ou privés. 


\title{
Self-Assembly and Fluorescence of Tetracationic Liquid Crystalline Tetraphenylethene
}

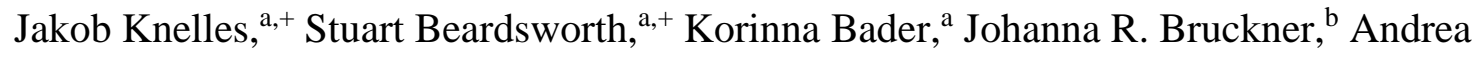

Bühlmeyer, ${ }^{\text {a }}$ Robert Forschner, ${ }^{a}$ Kevin Schweizer, ${ }^{\text {a }}$ Wolfgang Frey, ${ }^{a}$ Frank Giesselmann, ${ }^{\mathrm{b}}$

Yann Molard, ${ }^{\mathrm{c}}$ Sabine Laschat*a

a. Jakob Knelles, Dr. Stuart Beardsworth, Korinna Bader, Andrea Bühlmeyer, Robert Forschner, Kevin Schweizer, Dr. Wolfgang Frey, Prof. Dr. Sabine Laschat. Institut für Organische Chemie, Universität Stuttgart, Germany, Email: sabine.laschat@oc.unistuttgart.de

b. Dr. Johanna R. Bruckner, Prof. Dr. Frank Giesselmann. Institut für Physikalische Chemie, Universität Stuttgart, Germany

c. Prof Dr. Yann Molard. University of Rennes, CNRS, ISCR, UMR 6226, ScanMAT UMS 2001, Rennes, France.

$\dagger$ Both coauthors contributed equally to this work.

\begin{abstract}
A series of tetraguanidinium tetraphenylethene (TPE) arylsulfonates with different chain lengths was prepared via ionic self-assembly of tetraguanidinium TPE chloride and the respective methyl arylsulfonates. Liquid crystalline properties were studied by differential scanning calorimetry, polarizing optical microscopy and X-ray diffraction. Tetraguanidinium TPE arylsulfonates with chain lengths of $\mathrm{C}_{8}-\mathrm{C}_{12}$ displayed hexagonal columnar mesophases over a broad temperature range, while derivatives with longer chains showed oblique columnar phases. In solution all compounds displayed aggregation-induced emission behaviour. Temperature-dependent luminescence spectra of the bulk phase of the tetraguanidinium TPE arylsulfonate with $\mathrm{C}_{14}$ side chains revealed a strong luminescence both in the solid state and the oblique columnar mesophase. The emission behaviour was rationalized by a unique combination of restriction of intramolecular rotation of the TPE core, Coulomb interaction between the guanidinium cations and $\pi-\pi$ interactions of the anionic arylsulfonate moieties.
\end{abstract}

\section{Introduction}


During the last years, an increasing amount of research has been devoted to the development of novel tetraphenylethenes (TPEs) due to their fascinating properties such as reversible redox behaviour, ${ }^{[1]}$ oxidative photocyclization to diarylphenanthrenes, ${ }^{[2]}$ and more prominently their aggregation-induced emission (AIE) abilities. The latter led to a wide range of applications, such as chemical sensors, bioprobes, solid state dyes and optoelectronic devices. ${ }^{[3]}$ Additionally, TPEs are also interesting molecules when it comes to soft matter. For example, TPE derivatives bearing stereogenic centres in peripheral side chains were used as dopants for chirality transfer in calamitic and discotic liquid crystals. ${ }^{[4]}$ Furthermore, TPEs with functionalized peripheral units promoting nanoseggregation, were found to form thermotropic liquid crystals..$^{[2,5-9]}$ Up to now several AIE-active compounds with liquid crystalline phases have been reported. ${ }^{[10,11]}$ However, cationic TPEs which form liquid crystal phases are virtually unknown. ${ }^{[12]}$ Considering, that such ionic liquid crystals (ILC) ${ }^{[13]}$ with fluorophoric units should provide highly interesting materials for printable devices and luminescent inks, ${ }^{[14]}$ due to their adjustable polarity, this is worthy of intense research efforts.

We here report the synthesis, mesomorphic and emission properties of an ionic tetraguanidinium TPE. To the best of our knowledge, this is the first ILC composed of a rigid tetracationic TPE core and four anions with flexible alkyl chains (Scheme 1), which selfassembles into a highly ordered columnar phase. In addition, it shows a pronounced blue emission in the LC phase and bulk solid state.

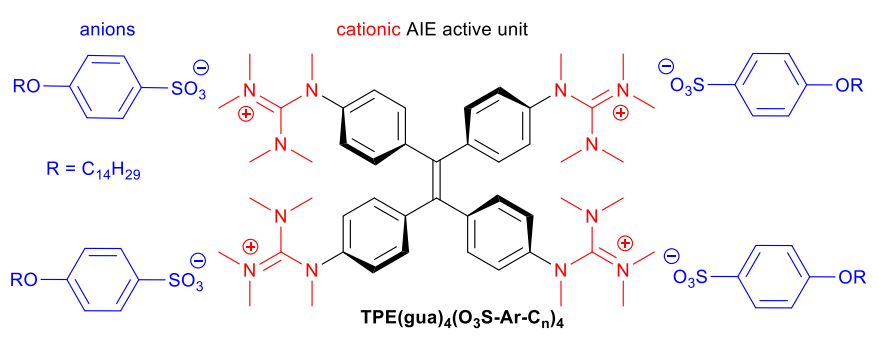

\section{Scheme 1}

\section{Results and Discussion}

The target compound TPE(gua) $)_{4}\left(\mathbf{O}_{3} \mathbf{S A r}\right)_{4}$ was synthesized in 5 steps with an overall yield of $12.8 \%$ from the known tetranitrotetraphenylethene TPE(NO$)_{4}{ }^{[15,16]}$ (Scheme 2, for further details see ESI $\dagger$ ). 


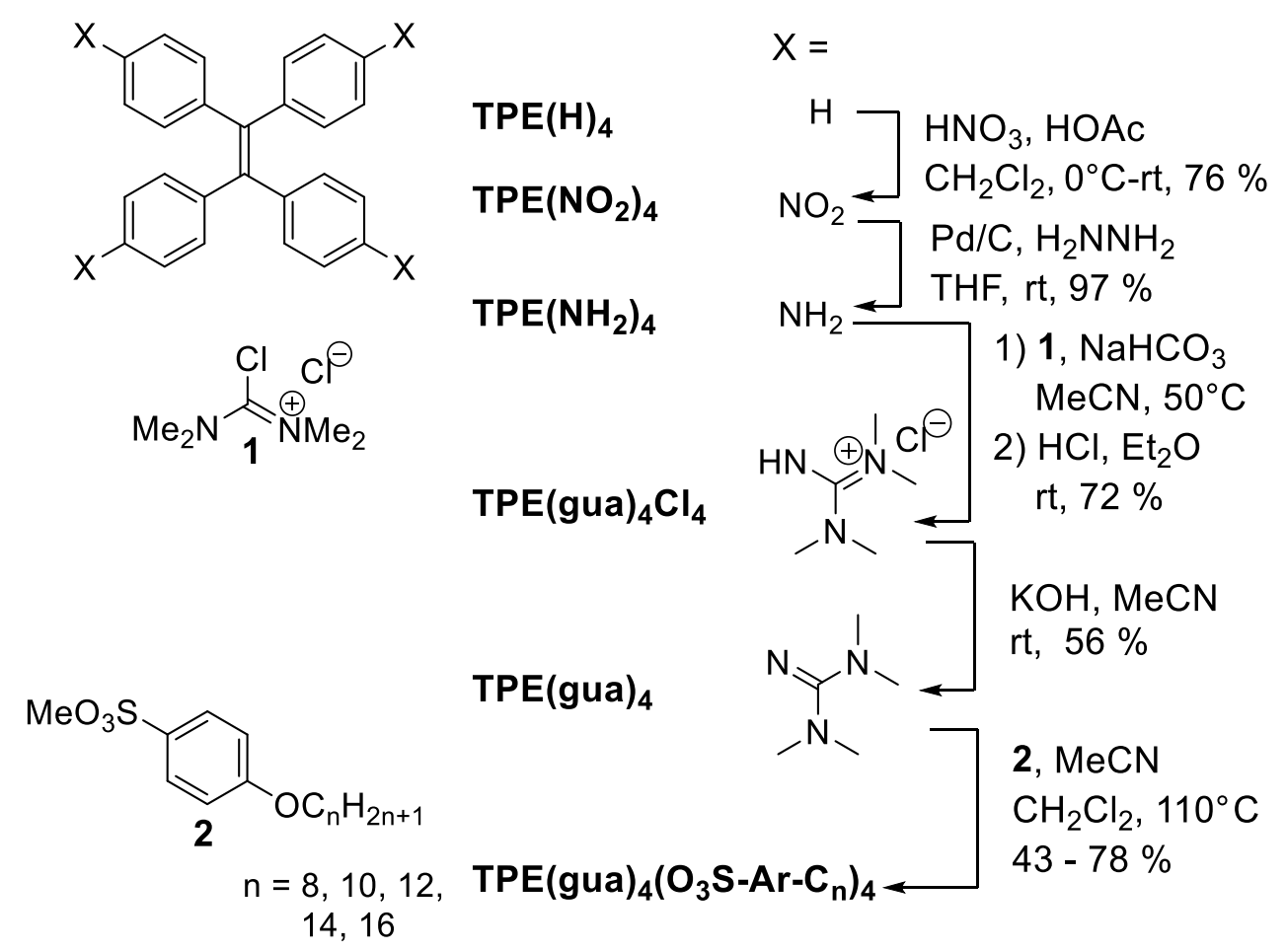

\section{Scheme 2}

Studies of $\mathbf{T P E}(\mathrm{gua})_{4}\left(\mathrm{O}_{3} \mathrm{~S}-\mathbf{A r}-\mathbf{C}_{n}\right)_{4}$ on their liquid crystalline properties lead to the assumption that all compounds form columnar mesophases. We suggest that $\mathbf{T P E}(\text { gua })_{4}(\mathbf{O} \mathbf{O} \mathbf{S}-$ Ar-C8)4, TPE(gua)4(O3S-Ar-C10)4, TPE(gua)4(O33-Ar-C12)4 with relatively short alkyl chains form $\mathrm{Col}_{\mathrm{h}}$ mesophases whereas TPE(gua $)_{4}\left(\mathrm{O}_{3} \mathrm{~S}-\mathrm{Ar}-\mathrm{C}_{14}\right)_{4}$ and TPE$(\text { gua })_{4}\left(\mathrm{O}_{3} \mathrm{~S}-\mathrm{Ar}\right.$ C16)4 form $\mathrm{Col}_{\mathrm{ob}}$ mesophases. In the following TPE(gua $)_{4}\left(\mathrm{O}_{3} \mathrm{~S}-\mathrm{Ar}-\mathrm{C}_{10}\right)_{4}$ and TPE(gua $)_{4}\left(\mathrm{O}_{3} \mathbf{S}-\mathbf{A r}-\mathrm{C}_{14}\right)_{4}$ are presented as examples for both cases. For further details, see $\mathrm{ESI} \dagger$.

When TPE(gua)4(O3S-Ar-C10)4 was studied by differential scanning calorimetry (DSC) an endothermal melting transition could be observed at $44{ }^{\circ} \mathrm{C}$ during the $1^{\text {st }}$ heating cycle, showing a rather small transition enthalpy. Upon further heating, clearing from the mesophase to the isotropic liquid took place at $100{ }^{\circ} \mathrm{C}$ during the $1^{\text {st }}$ heating cycle (Fig. 1). No transition could be observed in the other heating/cooling cycles. Upon cooling from the isotropic liquid a transition back into the liquid crystalline columnar phase occurred rather than a vitrification into a glassy state. This was supported by XRD experiments for $\mathbf{T P E}(\text { gua })_{4}\left(\mathrm{O}_{3} \mathrm{~S}-\mathrm{Ar}-\mathrm{C}_{10}\right)_{4}$ at different temperatures: $25^{\circ} \mathrm{C}$ (in the hexagonal columnar phase), $130^{\circ} \mathrm{C}$ (in the isotropic liquid) and at $25^{\circ} \mathrm{C}$ (after cooling from $130^{\circ} \mathrm{C}$ ) respectively, which revealed that the intensity of the (10) peak changed, but not the peak position thus precluding a vitrification (see Figure S31, ESI†). 

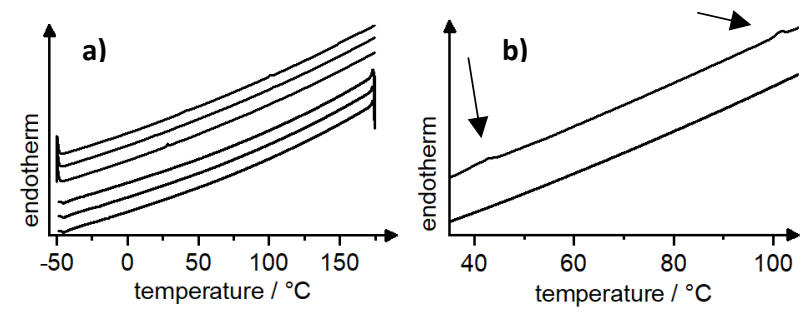

Fig. 1 a) DSC traces of TPE(gua) $)_{4}\left(\mathrm{O}_{3} \mathrm{~S}-\mathrm{Ar}-\mathrm{C}_{10}\right)_{4}$ with a maximum temperature of $175{ }^{\circ} \mathrm{C}$; A transition from $\mathrm{Cr}$ to $\mathrm{Col}_{\mathrm{h}}$ was observed at $44{ }^{\circ} \mathrm{C}$ and a transition from $\mathrm{Col}_{\mathrm{h}}$ to I was observed at $100{ }^{\circ} \mathrm{C}$ in the first heating only. b) Magnification of the $1^{\text {st }}$ heating and cooling cycle.

Upon heating TPE(gua) $4\left(\mathrm{O}_{3} \mathrm{~S}-\mathrm{Ar}-\mathrm{C}_{10}\right)_{4}$ under the polarized optical microscope (POM) above $44{ }^{\circ} \mathrm{C}$ fan like textures appeared, suggesting a columnar phase, until the transition into the isotropic liquid at $100{ }^{\circ} \mathrm{C}$ (Fig. 2).

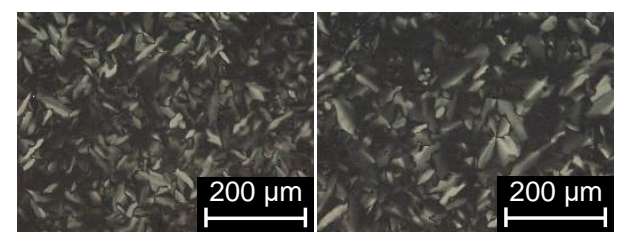

Fig 2: POM textures of $\mathbf{T P E}(\text { gua })_{4}\left(\mathrm{O}_{3} \mathrm{~S}-\mathrm{Ar}-\mathrm{C}_{10}\right)_{4}$ at $90{ }^{\circ} \mathrm{C}$. Magnification $\times 100$. Heating rate $5 \mathrm{~K} / \mathrm{min}$.

X-ray studies were performed on samples which were filled in mark capillaries by fiber extrusion. In the wide-angle section of TPE(gua) $4\left(\mathrm{O}_{3} \mathrm{~S}-\mathbf{A r}-\mathrm{C}_{10}\right)_{4}$ a broad halo around $2 \theta=18.74^{\circ}$ was visible due to the molten alkyl chains, revealing the liquid crystalline state (Fig. 3). The SAXS measurement showed 2 reflexes which were assigned to (10), (11) in a ratio of $1: \sqrt{3}$. This leads to the assumption of a columnar hexagonal phase, which agrees with the POM-pictures (Fig. 3).
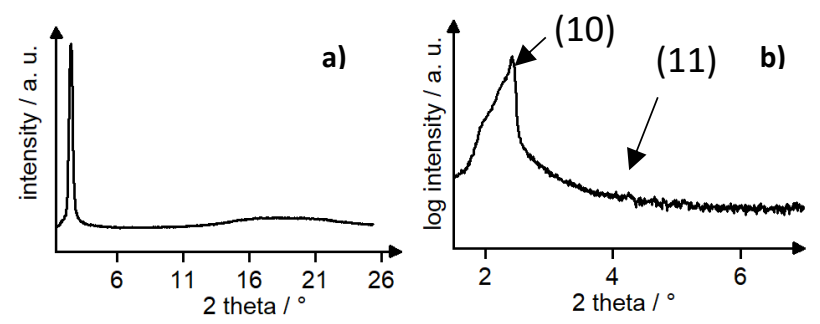

Fig. 3 1D-XRD results of TPE(gua) $)_{4}\left(\mathrm{O}_{3} \mathrm{~S}-\mathbf{A r}-\mathbf{C}_{10}\right)_{4}$. (a) WAXS at $90{ }^{\circ} \mathrm{C}$ and (b) SAXS at $90{ }^{\circ} \mathrm{C}$ measured while heating. Please note that the WAXS measurement was performed with a point collimated X-ray beam, while the SAXS measurement was obtained with a line collimated beam. The latter enables the detection of the faint (11) reflection but causes an asymmetric scattering peak. 
When TPE(gua) $)_{4}\left(\mathbf{O}_{3} \mathbf{S}-\mathbf{A r}-\mathbf{C}_{14}\right)_{4}$ was studied by DSC an endothermal melting transition was observed at $53{ }^{\circ} \mathrm{C}$ during the $1^{\text {st }}$ heating (Fig. 4a). Upon further heating above $200{ }^{\circ} \mathrm{C}$ thermal decomposition started. In order to avoid thermal decomposition repetitive heating/cooling cycles were run below $110{ }^{\circ} \mathrm{C}$ (Fig. 4b). The melting transition at $53{ }^{\circ} \mathrm{C}$ could be repeatedly observed in the $2^{\text {nd }}$ and $3^{\text {rd }}$ heating cycles. Similar behaviour and thermal decomposition at elevated temperatures were reported by Ren and $\mathrm{Lu}$ for tetraanionic and neutral TPEs, respectively $[12,8 \mathrm{a}]$. In the three cooling cycles, a phase transition could be detected at $25{ }^{\circ} \mathrm{C}$ showing a rather small transition enthalpy.

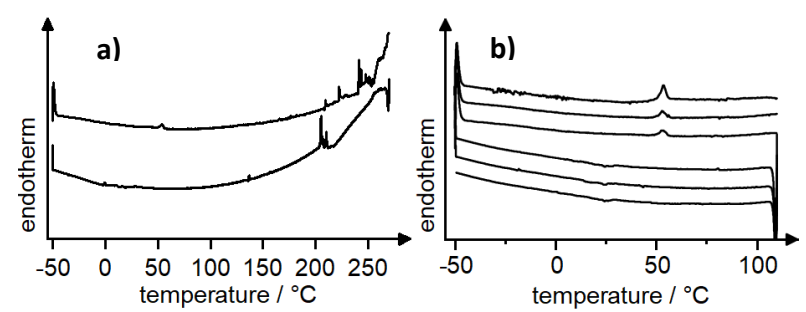

Fig. 4 DSC traces of $\mathbf{T P E}(\mathrm{gua})_{4}\left(\mathrm{O}_{3} \mathrm{~S}-\mathbf{A r}-\mathbf{C}_{14}\right)_{4}$ with a maximum temperature of: a) $270{ }^{\circ} \mathrm{C}$, $1^{\text {st }}$ heating, $1^{\text {st }}$ cooling; b) $110{ }^{\circ} \mathrm{C}$; transition temperature from $\mathrm{Cr}$ to $\mathrm{Col}_{\mathrm{ob}}$ : $53{ }^{\circ} \mathrm{C}$, heating/cooling rate $10 \mathrm{~K} / \mathrm{min}$.

Upon heating of $\mathbf{T P E}(\text { gua })_{4}\left(\mathrm{O}_{3} \mathrm{~S}-\mathrm{Ar}-\mathrm{C}_{14}\right)_{4}$ in the polarized optical microscope (POM) above $53{ }^{\circ} \mathrm{C}$ (Fig. 5), fan-shaped textures appeared, suggesting a columnar phase, which persisted until $230{ }^{\circ} \mathrm{C}$. At this temperature it either fully decomposed or the transition into the isotropic liquid phase appeared. In agreement with Tang's report on tetraalkinyl TPEs ${ }^{[6 b]}$ no textures were visible in the cooling cycle after thermal degradation.

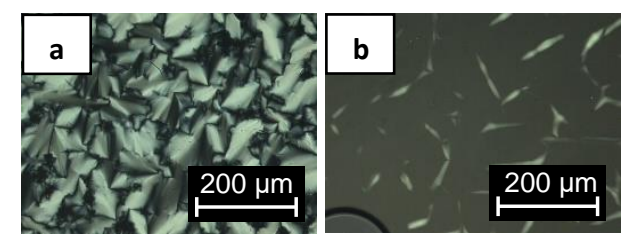

Fig 5 POM textures of TPE(gua $)_{4}\left(\mathrm{O}_{3} \mathrm{~S}-\mathrm{Ar}-\mathrm{C}_{14}\right)_{4}$ observed upon first heating at (a) $55^{\circ} \mathrm{C}$ and (b) $230{ }^{\circ} \mathrm{C}$ respectively. Magnification $\times 100$. Heating rate $5 \mathrm{~K} / \mathrm{min}$.

In X-ray diffraction a broad halo around $2 \theta=17.6^{\circ}$ was visible in the wide angle region due to the molten alkyl chains, revealing the liquid crystalline state (Fig.6a). The SAXS pattern consisted of 16 distinct reflexes, 10 of them appearing at $2 \theta=2.15^{\circ}$, while the other 6 can be found at $2 \theta=2.47^{\circ}$ (Fig $6 b$ ). 


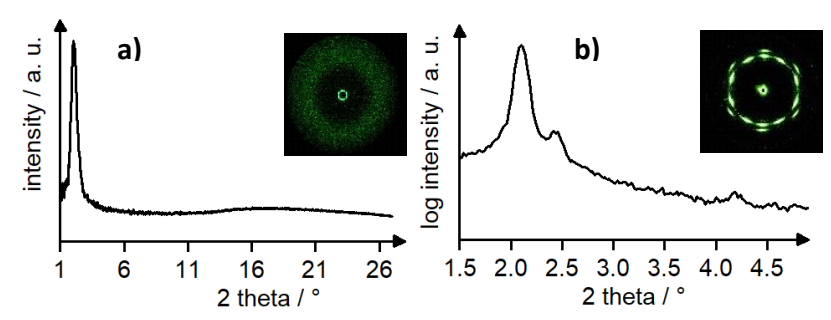

Fig. 6 1D-XRD results of TPE(gua) $)_{4}\left(\mathrm{O}_{3} \mathrm{~S}-\mathbf{A r}-\mathbf{C}_{14}\right)_{4}$. (a) WAXS at $110^{\circ} \mathrm{C}$ and (b) SAXS at $110^{\circ} \mathrm{C}$ measured while cooling; the insets show the corresponding two-dimensional X-ray scattering images of the mesophases. Both measurements were performed with point collimated X-ray beams.

This complex two-dimensional diffraction pattern hints at a columnar mesophase, which possess significantly less symmetry than the hexagonal phase. A possible way to explain the measured diffraction pattern is by assuming a superposition of scattering caused by several different domains.

We suggest that there are three distinct director orientations within the probed sample volume. In the first domain type, columns are oriented along the long axes of the mark capillary, which gives rise to the scattering along the vertical axis of the diffraction pattern (Fig 7).

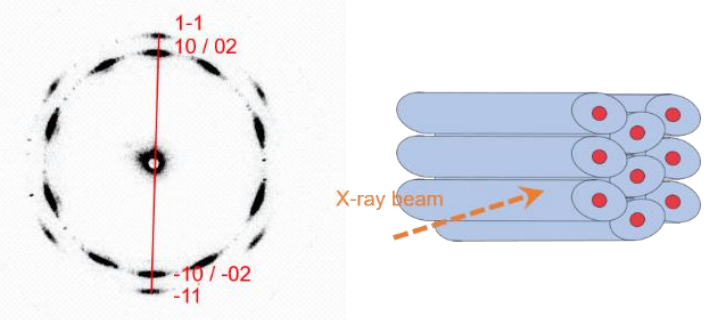

Fig. 7 Miller indices of the small angle scattering maxima appearing in vertical direction (left) and assumed sample orientation (right).

For the other two orientations, the columns point into the same direction as the X-ray beam and are mirror images of each other. The indexation of reflexes from one or the other mirrored domains are color-coded in green or purple, respectively (Fig 8). 


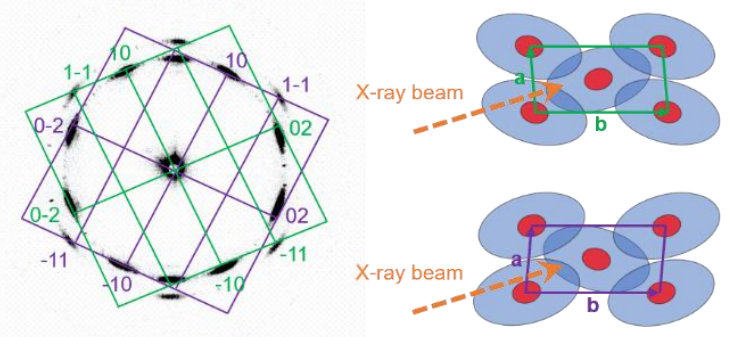

Fig. 8 Indexation of the diffraction pattern (left) corresponding to the two possible orientations of the oblique unit cell (right).

Similar results were found before by Zhang ${ }^{[17]}$ for a hexagonal columnar phase. Taking these considerations into account, an indexation according to the oblique plane group $p l$ results in the cell parameters $a=4.12 \mathrm{~nm}, b=8.24 \mathrm{~nm}$ and $\gamma=85.7^{\circ}$ (for the calculation see Table $\mathrm{S} 2$, ESI $\dagger$ ). Based on this, we suggest a packing model for the oblique columnar phase $\left(\mathrm{Col}_{\mathrm{ob}}\right)$ as shown in Fig. 9. Molecular modelling of TPE(gua $)_{4}\left(\mathbf{O}_{3} \mathbf{S}-\mathbf{A r}-\mathbf{C}_{14}\right)_{4}$ gave a diameter of 6.62 $\mathrm{nm}$ for the fully extended conformation and an inner diameter of $1.74 \mathrm{~nm}$ for the tetracationic core [18]. Comparison of the experimentally determined lattice parameter of the Colob phase with the values from molecular modeling suggest a significant interdigitation of the molten side chains. In contrast to the tetracarboxylate TPE by Ren, ${ }^{[12]}$ we did not find any evidence for a helix formation in the columnar phase.

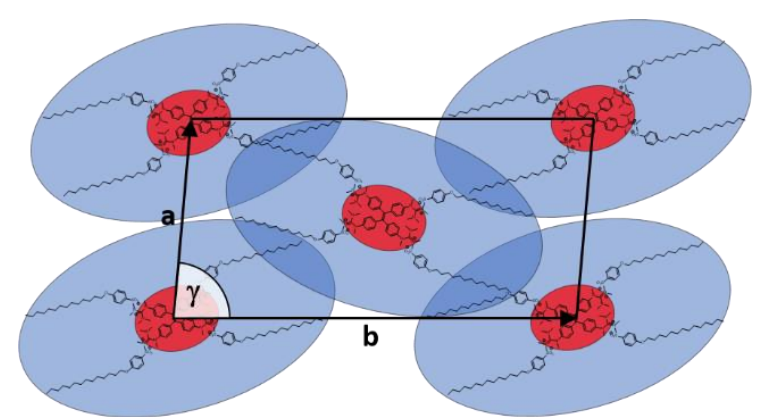

Fig. 9 Proposed packing model of TPE(gua $)_{4}\left(\mathrm{O}_{3} \mathrm{~S}-\mathrm{Ar}-\mathrm{C}_{14}\right)_{4}$ in the $\mathrm{Col}_{\mathrm{ob}}$ phase. Each column consists of an inner tetracationic core, which is highlighted in red and is surrounded by molten alkyl chains depicted in blue.

Examination of the UV/Vis spectra of guanidinium ILCs $\mathbf{T P E}(\text { gua })_{4}\left(\mathrm{O}_{3} \mathrm{~S}-\mathbf{A r}-\mathrm{C}_{\mathbf{n}}\right)_{4}$ in $\mathrm{MeCN}$ revealed a distinct absorption at $232 \mathrm{~nm}$ and a shoulder at $283 \mathrm{~nm}$ for all derivatives irrespective of the chain lengths. A typical example is shown for TPE(gua $)_{4}\left(\mathrm{O}_{3} \mathrm{~S}-\mathrm{Ar}-\mathrm{C}_{14}\right)_{4}$ in Figure 10 (For the absorption spectra of the other homologues see Figures S19-S23, ESI $\dagger$ ). 


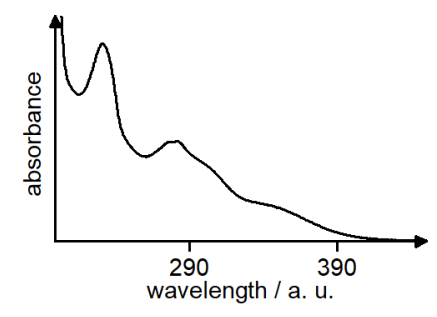

Fig 10 UV/VIS spectrum of TPE(gua $)_{4}\left(\mathbf{O}_{3} \mathbf{S}-\mathbf{A r}-\mathbf{C}_{14}\right)_{4}(c=17.1 \mu \mathrm{M})$ shown exemplarily for all chain lengths.

Upon irradiation at $359 \mathrm{~nm}$, dilute $\mathrm{MeCN}$ solutions of $\mathbf{T P E}(\text { gua })_{4}\left(\mathbf{O}_{3} \mathbf{S}-\mathbf{A r}-\mathbf{C}_{n}\right)_{4}$ showed a blue-green emission (Figures S19 - S23, ESI $\dagger$ ). Next, fluorescence spectra of each homologue with increasing amount of antisolvent were studied. Due to the water solubility of these ILCs water could not be used as antisolvent and therefore THF was employed.
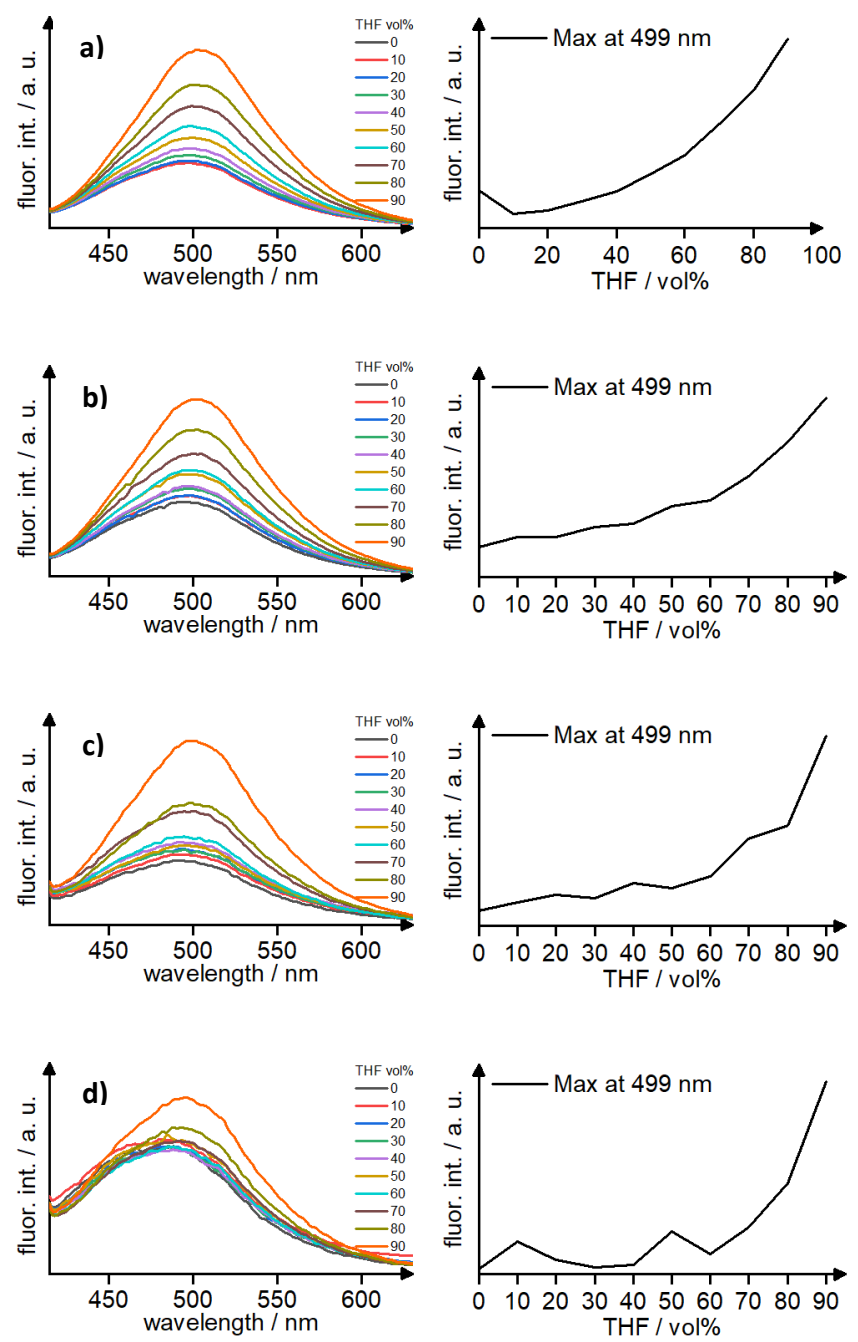


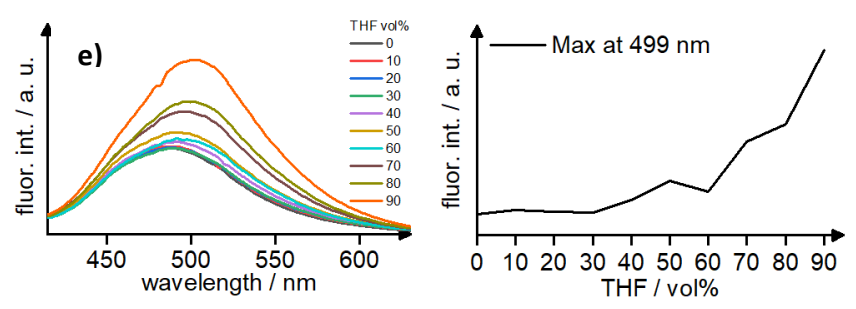

Fig 11 Fluorescence spectra of TPE(gua $)_{4}\left(\mathbf{O}_{3} \mathbf{S}-\mathbf{A r}-\mathbf{C}_{n}\right)_{4}(n=8-16$; (only even numbers); a-e) in MeCN/THF mixtures at $\lambda_{\mathrm{exc}}=359 \mathrm{~nm}, \mathrm{c}=1 \mu \mathrm{M}$ (left) and the relative emission intensity at $\lambda_{\text {max }, \mathrm{em}}=499 \mathrm{~nm}$ at different volumetric fractions of antisolvent (right).

The emission spectra in Figure 11 (left) and the corresponding intensity vs. volume fraction of antisolvent curves (Figure 11, right) clearly revealed, that for all chain lengths the emission intensity increased with increasing antisolvent concentration showing AIE behaviour.

In order to get some insight regarding the role of the tetracationic guanidinium TPE core on the solution emission of $\mathbf{T P E}(\text { gua })_{4}\left(\mathbf{O}_{3} \mathbf{S}-\mathbf{A r}-\mathbf{C}_{n}\right)_{4}$ the corresponding synthetic precursors TPE(NO$\left.)_{4}\right)_{4}$ TPE(gua ${ }_{4} \mathrm{Cl}_{4}$ and TPE(gua) 4 were studied. (Fig. 12; for UV/Vis data see Fig. S $16-\mathrm{S} 18$ and Table S1, ESI $\dagger$ ).
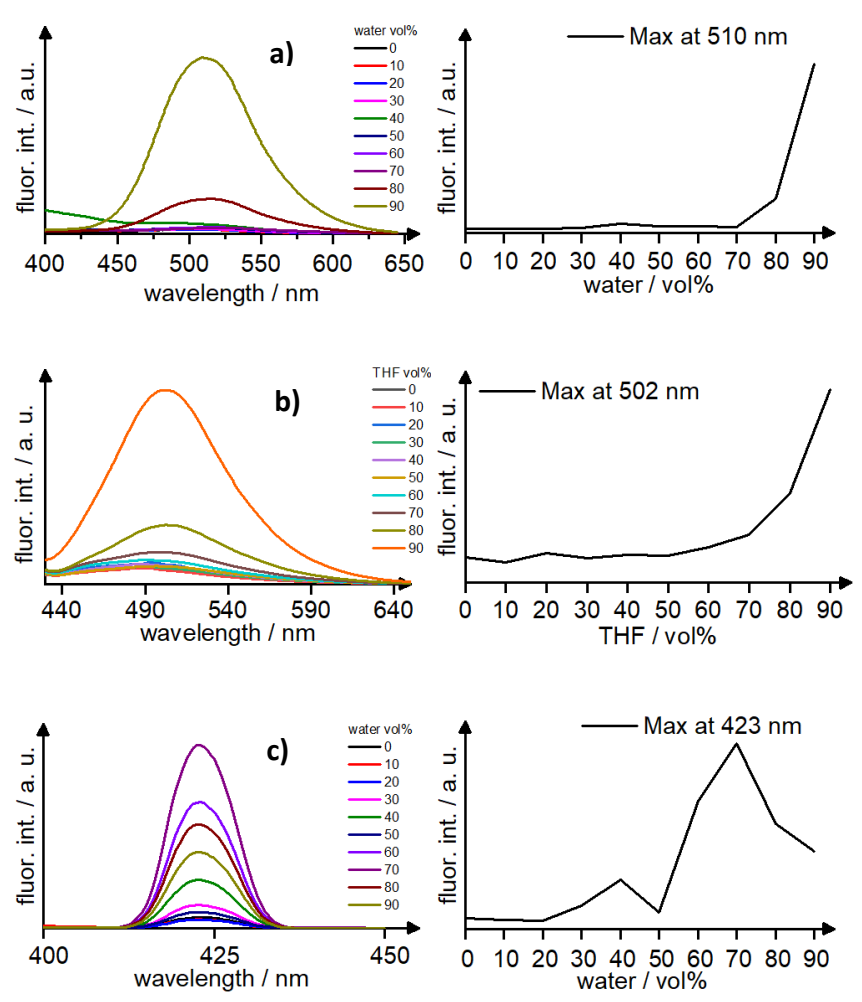

Fig 12 Fluorescence spectra of TPE derivatives in solvent/antisolvent mixtures (left) and the relative emission intensity at $\lambda_{\text {max,em }}$ at different volumetric fractions of antisolvent (right). (a) 
TPE(NO$)_{4}$ in THF/water mixtures $\left(\lambda_{\max , \mathrm{em}}=510 \mathrm{~nm}, \mathrm{c}=1.56 \mu \mathrm{M}, \lambda_{\mathrm{exc}}=325 \mathrm{~nm}\right),(\mathrm{b})$ TPE(gua) ${ }_{4} \mathrm{Cl}_{4}$ in MeCN/THF mixtures $\left(\lambda_{\max , \mathrm{em}}=502 \mathrm{~nm}, \mathrm{c}=0.97 \mu \mathrm{M}, \lambda_{\mathrm{exc}}=380 \mathrm{~nm}\right)$, (c) TPE(gua) 4 in THF/water mixtures $\left(\lambda_{\max , \mathrm{em}}=423 \mathrm{~nm}, \mathrm{c}=0.38 \mu \mathrm{M}, \lambda_{\mathrm{exc}}=304 \mathrm{~nm}\right)$.

TPE(NO$)_{4}$ was almost non-fluorescent both in THF solution and in THF/water mixtures with increasing water fraction $\left(f_{w}\right)$ (Fig. 12a). ${ }^{[19]}$ At $f_{w}>70$ vol\% a green emission at $510 \mathrm{~nm}$ appeared, which became stronger upon further increase of the antisolvent concentration, revealing archaetypal AIE behaviour. ${ }^{[3]}$

A solution of TPE(gua) ${ }_{4} \mathbf{C l}_{4}$ in $\mathrm{MeCN}$ displayed almost no fluorescence, which changed upon addition of the antisolvent THF (Fig. 12b). At $\mathrm{f}_{\mathrm{THF}}=70 \mathrm{vol} \%$ a green emission at $502 \mathrm{~nm}$ appeared. The fluorescence intensity increased upon further addition of the antisolvent concentration. This is in comparison with $\mathbf{T P E}\left(\mathbf{N O}_{2}\right)_{4}$, showing the typical AIE behaviour.

The neutral counterpart TPE(gua)4 was almost non-emissive in pure THF and THF/water mixtures with $f_{w} \leq 20$ vol\% (Fig. 12c). At higher $f_{w}$ a distinct pale blue emission at $423 \mathrm{~nm}$ appeared, which besides a sudden drop at $\mathrm{f}_{\mathrm{w}}=50 \mathrm{vol} \%$ increased until $70 \mathrm{vol} \%$ and then decreased again. Sudden drops of the emission intensity were reported by Lai and Cho ${ }^{\text {[11a, } 7 \mathrm{~b}]}$ and rationalized as turbidity due to emulsion formation or precipitation of aggregates. However, we found no visible evidence for precipitation nor emulsion.

In the bulk solid state at room temperature TPE(gua) $)_{4}\left(\mathrm{O}_{3} \mathrm{~S}-\mathbf{A r}-\mathrm{C}_{14}\right)_{4}$ emitted a green fluorescence at $504 \mathrm{~nm}$ (Fig. 13). At $55^{\circ} \mathrm{C}$ in the $\mathrm{Col}_{\mathrm{ob}}$ the emission intensity was still $87 \%$. Upon further increasing the temperature, the emission decreased until the weakly emissive isotropic liquid was obtained at $230^{\circ} \mathrm{C}$. When the subsequent cooling cycle was run before the onset of degradation, the fluorescence could be fully recovered (Fig. S 14, ESI $\dagger$ ). A decreasing emission intensity with increasing temperature is well known for columnar and smectic AIE active liquid crystals and is caused by the increased thermal rotation of the TPE aryl units and enhanced non-radiative relaxation of the flexible alkyl chains. ${ }^{[7 a, b, 11]}$ However, for the bulk sample of $\mathbf{T P E}(\text { gua })_{4}\left(\mathrm{O}_{3} \mathrm{~S}-\mathrm{Ar}-\mathrm{C}_{14}\right)_{4}$ the maximal emission wavelength remained unaffected by the temperature.

Comparison of bulk and solution emission revealed a much broader emission peak in the latter case (Fig. 13). As has been discussed by $\operatorname{Ren}^{[12,22]}$ the columnar self-assembly of propeller-shaped ILCs such as TPE(gua) $)_{4}\left(\mathbf{O}_{3} \mathbf{S}-\mathbf{A r}-\mathbf{C}_{14}\right)_{4}$ both in solution and bulk state differs from conventional discotic mesogens, because the propeller-shaped mesogenic core prohibits $\pi-\pi$ interaction of the TPE aryl units. 


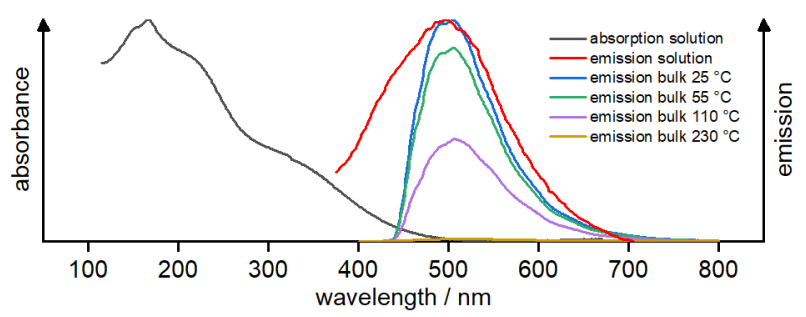

Fig. 13 Absorption spectrum of TPE(gua) $)_{4}\left(\mathrm{O}_{3} \mathrm{~S}-\mathrm{Ar}-\mathrm{C}_{14}\right)_{4}$ in dilute $\mathrm{MeCN}$ solution (black), the corresponding emission spectra in dilute $\mathrm{MeCN}$ solution (red, $\lambda_{\mathrm{ex}}=359 \mathrm{~nm}$ ) and in the bulk state $\left(\lambda_{\mathrm{ex}}=380-420 \mathrm{~nm}\right)$ at different temperatures: $25^{\circ} \mathrm{C}$ (blue), $55^{\circ} \mathrm{C}$ (green), $110^{\circ} \mathrm{C}$ (magenta), $230^{\circ} \mathrm{C}$ (yellow).

Furthermore, intracolumnar Coulomb repulsion between guanidinium cations might lead to helical twisting of the columnar aggregate as was observed by Ren for tetraanionic ILCs. ${ }^{[12]}$ However, as discussed above, our XRD data did not give any indication for helical packing, but supported instead a perpendicularly stacked packing.

The major driving forces for mesophase stabilization are electrostatic interactions between ion pairs, favorable $\pi-\pi$ interaction of the aryl sulfonate anions and van der Waals interactions of the peripheral alkoxy side chains, which promote nanoseggregation. Our results indicate that in the bulk solid and columnar mesophase the restriction of aryl rotation of the TPE unit is more important for the overall emission behaviour than potential H-type $\pi-\pi$ stacking of the arylsulfonate anions. On the other hand, in concentrated solutions TPE aryl rotation is somehow restricted, but the influence of peripheral arylsulfonates becomes more prominent, suppressing fluorescence emission through H-aggregates. ${ }^{[3,23]}$ For the neutral TPE(gua)4, where only the rotationally restricted TPE unit is present without the arylsulfonate anion, pronounced fluorescence emissions at higher antisolvent concentrations were detected.

\section{Conclusion}

In conclusion, we presented the first tetracationic TPE ILC self-assembling into $\mathrm{Col}_{\mathrm{h}}$ phases for chain lengths $\mathrm{C}_{8}, \mathrm{C}_{10}$ and $\mathrm{C}_{12}$, whereas homologues with $\mathrm{C}_{14}$ and $\mathrm{C}_{16}$ chains form $\mathrm{Col}_{\mathrm{ob}}$ mesophases. Our results revealed, that the emission behaviour of the aggregates both in concentrated solution as well as in the bulk columnar mesophase is dominated by a combination of restricted intramolecular rotation of the TPE aryls and Coulomb interaction between the guanidinium cations and is further stabilized by favourable $\pi-\pi$ interactions of the anionic arylsulfonate moieties. This stabilizing effect of the arylsulfonate was deduced from the redshift of the emission of $\mathbf{T P E}(\text { gua })_{4}\left(\mathrm{O}_{3} \mathbf{S}-\mathbf{A r}-\mathbf{C}_{n}\right)_{4}$ in solution as compared to TPE(gua)4 respectively. The observed redshift between $\mathbf{T P E}(\text { gua })_{4}\left(\mathrm{O}_{3} \mathrm{~S}-\mathrm{Ar}-\mathrm{C}_{14}\right)_{4}$ in the bulk 
solid or columnar mesophase as compared to the concentrated solution further supports the stabilizing effect of the arylsulfonate counterion. Thus, TPE(gua $)_{4}\left(\mathrm{O}_{3} \mathrm{~S}-\mathbf{A r}-\mathbf{C}_{n}\right)_{4}$ are promising AIE-active materials suitable for bulk processing, complement non-polar chromophors $^{[14,24]}$ and provide useful guidelines for the design of emissive ILC-based materials for luminescent inks and printable OLED devices.

\section{Conflicts of interest}

There are no conflicts to declare.

\section{Acknowledgements}

Generous financial support by the DFG (LA 907/20-1 SNAPSTER), the ANR (ANR-18CE92-0026), the Fonds der Chemischen Industrie (Kekulé fellowship for S.B.) and the CarlSchneider Stiftung Aalen (instrumentation grant) is gratefully acknowledged. We would like to thank Justus Back for help with the fluorescence measurements and Prof. Sabine Ludwigs for kind support.

Keywords: aggregation-induced emission, fluorescence, liquid crystals, ionic self-assembly, tetraphenylethene

\section{Notes and references}

[1] a) R. Rathore, S. V. Lindeman, A. S. Kumar, J. K. Kochi, J. Am. Chem. Soc. 1998, 120, 6931-6939; b) F. Barbosa, V. Peron, G. Gescheidt, A. Fürstner, J. Org. Chem. 1998, 63, 8806-8814.

[2] a) C. E. Bunker, N. B. Hamilton, Y.-P. Sun, Anal. Chem., 1993, 65, 3460-3465; b) A. Schultz, S. Laschat, S. Diele, M. Nimtz, Eur. J. Org. Chem., 2003, 2829-2839; d) L. Zhu, R. Wang, L. Tan, X. Liang, C. Zhong, F. Wu, Chem. Asian J., 2016, 11, 2932-2937; e) J. Ma, T. Lin, X. Pan, W. Wang, Chem. Mater., 2014, 26, 4221-4229; f) A. Prlj, N. Doslic, C. Corminboeuf, Phys. Chem. Chem. Phys., 2016, 18, 11606-11609; g) G. Huang, B. Ma, J. Chen, Q. Peng, G. Zhang, Q. Fan, D. Zhang, Chem. Eur. J., 2012, 18, 3886-3892; h) T. Takeda, S. Yamamoto, M. Mitsuishi, T. Akutagawa, Org. Biomol. Chem., 2016, 14, 89228926.

[3] a) Z. Song, W. Zhang, M. Jiang, H. H. Y. Sung, R. T. K. Kwok, H. Nie, I. D. Williams, B. Liu, B. Z. Tang, Adv. Func. Mater., 2016, 26, 824-832; b) B. Situ, S. Chen, E. 
Zhao, C. W. T. Leung, Y. Chen, Y. Hong, J. W. Y. Lam, Z. Wen, W. Liu, W. Zhang, L. Zheng, B. Z. Tang, Adv. Func. Mater. 2016, 26, 7132-7138; c) Y. J. Wang, Y. Shi, Z. Wang, Z. Zhu, X. Zhao, H. Nie, J. Qian, A. Qin, J. Z. Sun, B. Z. Tang, Chem. Eur. J., 2016, 22, 9784-9791; d) Q. Zhang, Y.-C. Liu, D.-M. Kong, D. S. Guo, Chem. Eur. J., 2015, 21, 1325313260; e) Q. Qi, J. Qian, X. Tan, J. Zhang, L. Wang, B. Xu, B. Zou, W. Tian, Adv. Func. Mater., 2015, 25, 4005-4010; f) Z. Zhao, J. W. Y. Lam, B. Z. Tang, J. Mater. Chem., 2012, 22, 23726-23740. Recent AIE reviews: h) J. Mei, Y. Hong, J. W. Y. Lam, A. Qin, Y. Tang, B. Z. Tang, Adv. Mater., 2014, 26, 5429-5479; i) J. Mei, N. L. C. Leung, R. T. K. Kwok, J. W. Y. Lam, B. Z. Tang, Chem. Rev., 2015, 115, 11718-19940.

[4] A. Schreivogel, U. Dawin, A. Baro, F. Giesselmann, S. Laschat, J. Phys. Org. Chem., 2009, 22, 484-494.

[5] W.-H. Yu, C. Chen, P. Hu, B.-Q. Wang, C. Redshaw, K.-Q. Zhao, RSC Adv., 2013, 3, 14099-14105.

[6] a) W.Z. Yuan, Z.-Q. Yu, P. Lu, C. Deng, J. W. Y. Lam, Z. Wang, E.-Q. Chen, Y. Ma, B. Z. Tang, J. Mater. Chem., 2012, 22, 3323-3326; b) D. Zhao, F. Fan, J. Cheng, Y. Zhang, K. S. Wong, V. G. Chigrinov, H. S. Kwok, L. Guo, B. Z. Tang, Adv. Opt. Mater., 2015, 3, 199-202. c); D. Zhao, H. He, X. Gu, L. Guo, K. S. Wong, J. W. Y. Lam, B. Z. Tang, Adv. Opt. Mater., 2016, 4, 534-539.

[7] a) H. T. Bui, J. Kim, H.-J. Kim, B.-K. Cho, S. Cho, J. Phys. Chem. C, 2016, 120, 26695-26702. b) S.-B. Han, H.-J. Kim, D. Jung, J. Kim, B.-K. Cho, S. Cho, J. Phys. Chem. C, 2015, 119, 16223-16229. c) J. Kim, S. Cho, B.-K. Cho, Chem. Eur. J., 2014, 20, 12734 12739 .

[8] a) Q. Ye, D. Zhu, H. Zhang, X. Lu, Q. Lu, J. Mater. Chem. C., 2015, 3, 6997-7003. b) J. Wu, Z. Yi, X. Lu, S. Chen, Q. Lu, Polymer Chem., 2014, 5, 2567-2573.

[9] A. Schultz, S. Diele, S. Laschat, M. Nimtz, Adv. Funct. Mater., 2001, 11, 441-446.

[10] a) X. Yang, X. Wu, D. Zhou, J. Yu, G. Xie, D. W. Bruce, Y. Wang, Dalton Trans., 2018, doi: 10.1039/c8dt03017k. b) C.-Y. Yu, C.-C. Hsu, H.-C. Weng, RSC Adv., 2018, 8, 12619-12627. c) Y. Wang, Y. Liao, C. P. Cabry, D. Zhou, G. Xie, Z. Qu, D. W. Bruce, W. Zhu, J. Mater. Chem. C, 2017, 5, 3999-4008. d) S. K. Pathak, B. Pradhan, R. K. Gupta, M. Gupta, S. K. Pal, A. S. Achalkumar, J. Mater. Chem. C, 2016, 4, 6546-6561.

[11] For ILCs with other AIE-active units see: a) R. T. Wang, G.-H. Lee, C. K. Lai, J. Mater. Chem., 2018, 6, 9430-9444. b) K. Tanabe, D. Kodama, M. Hasegawa, T. Kato, Chem. Lett., 2014, 43, 184-186. c) K. Tanabe, Y. Suzui, M. Hasegawa, T. Kato, J. Am. Chem. Soc., 2012, 134, 5652-5661. 
[12] For a tetraanionic TPE see: H. Jing, L. Lu, Y. Feng, J.-F. Zheng, L. Deng, E.-Q. Chen, X.-K. Ren, J. Phys. Chem. C., 2016, 120, 27577-27586.

[13] Recent reviews: a) K. Goossens, K. Lava, C. W. Bielawski, K. Binnemans, Chem. Rev., 2016, 116, 4643-4807; b) K. V. Axenov, S. Laschat, Materials, 2011, 4, 206-259; c) M. Mansueto, S. Laschat, Handbook of Liquid Crystals, J. W. Goodby, P. J. Collings, T. Kato, C. Tschierske, H. Gleeson, P. Raynes (eds.), 2nd ed., Wiley-VCH, Weinheim, 2014, vol. 6, 231280; d) L. Douce, J.-M. Suisse, D., A. Taubert, Liq. Cryst., 2011, 38, 1653-1661; e) S. Chen, S. H. Eichhorn, Isr. J. Chem., 2012, 52, 830-843; f) V. Causin, G. Saielli, Green Solvents II: Properties and Applications of Ionic Liquids, A. M. Imamuddin, Springer, Dordrecht, 2012, 79-118.

[14] a) A. Gosh, T. Nakanishi, Chem. Commun., 2017, 53, 10344-10357. b) S. S. Babu, M. J. Hollamby, J. Aimi, H. Ozawa, A. Saeki, S. Seki, K. Kobayashi, K. Hagiwara, M. Yoshizwa, H. Möhwald, T. Nakanishi, Nat. Commun., 2013, 4, 1969.

[15] A. Schreivogel, J. Maurer, R. Winter, A. Baro, S. Laschat, Eur. J. Org. Chem., 2006, $3395-3404$.

[16] Anuradha, D. D. La, M. Al Kobaisi, A. Gupta, S. V. Bhosale, Chem Eur J., 2017, 23, 3950-3956.

[17] R. Zhang, X. Zeng, B. Kim, R. J. Bushby, K. Shin, P. J. Baker, V. Percec, P. Leuwanawat, G. Ungar, ACS Nano, 2015, 9, 1759-1766.

[18] Software Avogadro, Version 1.11 for details see; M, D, Hanwell, D. E. Curtis, D. C. Louie, T. Vandermeersch, E. Zurck, G. R. Hutchison, J. Cheminf., 2012, 4, 17.

[19] Although TPE(NO2)4 has been used as intermediate in refs. [15, 16], to the best of our knowledge the optical properties have not been reported to date.

[20] T. Noguchi, T. Shiraki, A. Dawn, Y. Tsuchiya, L. T. N. Lien, T. Yamamoto, S. Shinkai, Chem. Commun., 2012, 48, 8090-8092.

[21] W. N. George, M. Giles, J. Mc Culloch, J. H. G. Steinke, J. C. de Mello, ChemPhysChem, 2011, 12, 765-768.

[22] S. K. Pathak, B. Pradhan, M. Gupta, S. K. Pal, A. A. Sudhakar, Langmuir, 2016, 32, 9301-9312.

[23] J. B. Birks, Photophysics of Aromatic Molecules, Wiley, London, 1970.

[24] a) J.-H. Olivier, F. Camerel, G. Ulrich, J. Barbera, R. Ziessel, Chem. Eur. J., 2010, 16, 7134-7142. b) J.-H. Olivier, J. Barbera, E. Bakaidarak, A. Harriman, R. Ziessel, J. Am. Chem. Soc., 2012, 134, 6100-6103. c) F. D’Anna, S. Marullo, G. Lazzara, P. Vitale, R. Noto, Chem. Eur. J., 2015, 21, 14780-14790. 


\section{Table of Contents entry}

Aggregation matters: the self-assembly of ionic liquid crystals based on tetracationic tetraphenylethene and arylsulfonate counterions resulted in stable columnar mesophases and strong fluorescence emission both in the bulk mesophase as well as in concentrated solution. X-Ray diffraction provided insight into the mesophase geometries revealing hexagonal columnar phases for tetraphenylethene ionic liquid crystals with side chain lengths of $\mathrm{C}_{8}-\mathrm{C}_{12}$ and oblique columnar phases for derivatives with $\mathrm{C}_{14}-\mathrm{C}_{16}$ chains.
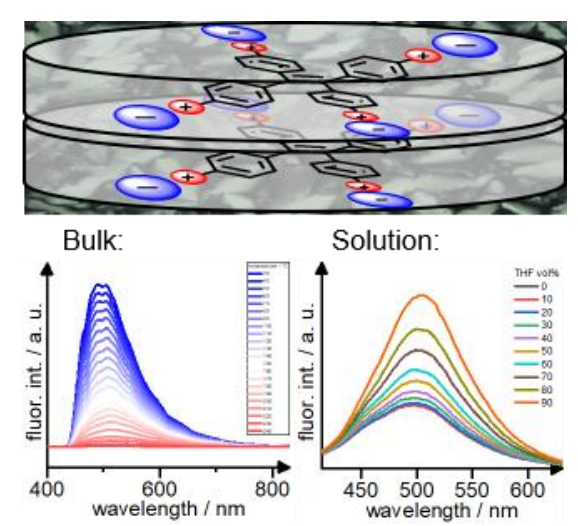